Published as: A.S. Arief and A.D.S. Gillies. A practical test of coal spontaneous combustion. Proceedings Aust. Inst.Min. Metall. Conference, March 1995, pp 111-114. 


\title{
A Practical Test of Coal Spontaneous Combustion
}

\author{
A S Arief ${ }^{1}$ and A D S Gillies ${ }^{1}$
}

\begin{abstract}
A device has been developed for modelling the behaviour of coal under conditions which may lead to spontuneous combustion. It is designed to model the behaviour of a stockpile of large mass. The apparatus can test coal samples taken from the flow stream from mine through washing, stockpiling and transportation to the point of utilisation. It tests samples in an 'as received' condition and so takes into account the effect of aspects such as particle size and moisture content on propensity for spontaneous combustion to occur. Results of the prelininary tests undertaken are given and future applications of the apparatus are discussed.
\end{abstract}

\section{INTRODUCTION}

Spontaneous combustion of coal is not a new problem to the mining and coal utilisation industries. Technological development in cutting coal to finer size fractions, more use of water for dust suppression, use of larger stockpiles, more complex washery processes and transport over longer distances may lead to a greater propensity to spontaneous combustion.

A project is being undertaken to establish if there is a significant increase in likely spontaneous combustion as a unit of coal passes from the mine face along the flowpath of transport, stockpiling, washing, transport and stockpiling to the point of utilisation. Most established tests on spontaneous combustion are based on the use of a relatively small sample of ground and dry coal. These approaches do not allow for, for instance, the testing of the relative difference in propensity to spontaneous combustion of coals of different particle size or total moisture. A column apparatus has been developed to allow testing of these relevant parameters. The column is insulated and acts to model the behaviour of stored coal (such as stockpiled coal) while allowing permeation of low air flow rates. This physical model is described and results of some preliminary tests on mined coal arc analysed.

\section{GENERAL PROBLEMS OF SPONTANEOUS COMBUSTION}

The phenomenon of the self heating of coal has been recognised for a long time. Although the spontancous combustion phenomenon is complex and not fully understood, most researchers have agreed that the spontancous combustion of coal is related to the accumulation of heat produced through oxidation processes.

Isobe and Higuchi (1981) stated that when coal interacts with oxygen, some heat will be liberated and if the environment allows accumulation of this heat, spontaneous heating is initiated. In relation to the oxidation process, Humphreys and Hester (1994) pointed out that the following steps are thought to be involved:

1. Adsorption of oxygen on the surface of coal and formation of complex molecular structures.

2. As the temperature increases breakdown of these complex structures releasing carbon monoxide.

3. Continuation of the breakdown of the surface structures and onset of a self-sustaining oxidation process and creation of increasing quantities of carbon monoxicle.

1. Department of Mining and Metallurgical Engineering. The University of Queensland.
If the quantity of air available to the exposed coal surfaces is low, the rate of oxidation is slow and a steady state is reached whereby heat generation is limited by the avalability of oxygen. If the air quantity is higher, the heat is dissipated as quickly as it is generated and this cooling effect may be adequate to prevent any significant rise in temperature. This in turn will limit the oxidation rate. In this case, equilibrium is maintained by removal of heat by the airflow and oxidation will occur only at low temperature. The total rate of oxidation which occurs at these two steady state conditions determines the normal or background level of carbon monoxide. Should this equilibrium be destroyed by either an increase in airflow or decrease in airflow through areas which have been cooled by airflow, then the temperature will rise and spontaneous combustion will result.

Based on this basic knowledge, several approaches have been developed to determine the liability of coal to spontaneous combustion. Most of them relate to recording temperature rise as an oxidation process occurs. Some attempts have also been made to undertake laboratory experiments which simulate as closely as possible what happens in the field. It is not the intention of this paper to discuss in detail the various methods that have been developed to determine the propensity of coal to spontaneous combustion. However, there is general agreement that it was not easy to simulate the situation in the field by laboratory experiments. Stott and Chen (1992) developed a concept to build apparatus which can follow the complete process of spontaneous heating. This approach which has been more fully explained by Chen (1991) was designated as the 'Full Scale Experiments Apparatus'. The principle of this test is to measure temperature rise of coal under adiabatic conditions. This is achieved by passing regulated rates of airflow through an insulated vertically mounted cylindrical tube of $2 \mathrm{~m}$ length. Coal samples used however, were crushed to minus $4 \mathrm{~mm}$ size.

The concepts developed by Chen (1991) and Stott and Chen (1992) have been incorporated in a modified model for spontaneous combustion testing. However, the modified apparatus is designed to test uncrushed coal as being more representative of conditions found at the minesite and in subsequent transportation and stockpiling prior to utilisation. From a practical point of view, size of the apparatus is such that the amount of sample needed to undertake the experiments is relatively small and apparatus can be handled easily by one person.

\section{THE PRACTICAL MODEL FOR SPONTANEOUS COMBUSTION TESTING}

This apparatus consists of a vertically mounted cylindrical tube $2 \mathrm{~m}$ long and of diameter $200 \mathrm{~mm}$. A schematic diagram is shown in Figure 1. The wall of the column consists of insulation (kaowool), steel and nylon carpet. The interior lining of carpet allows coal to press against the cylinder interior wall and stops channelling of air against the wall. The temperature at the centre and on the outside of the steel column is recorded at eight different positions equally spaced along the column. Wrap around heating elements are wound at eight positions along the column to minimise heat transfered from inside the tube to the surrounding atmosphere. All thermocouples are connected to a computer. Computer software activates the heating elements if 


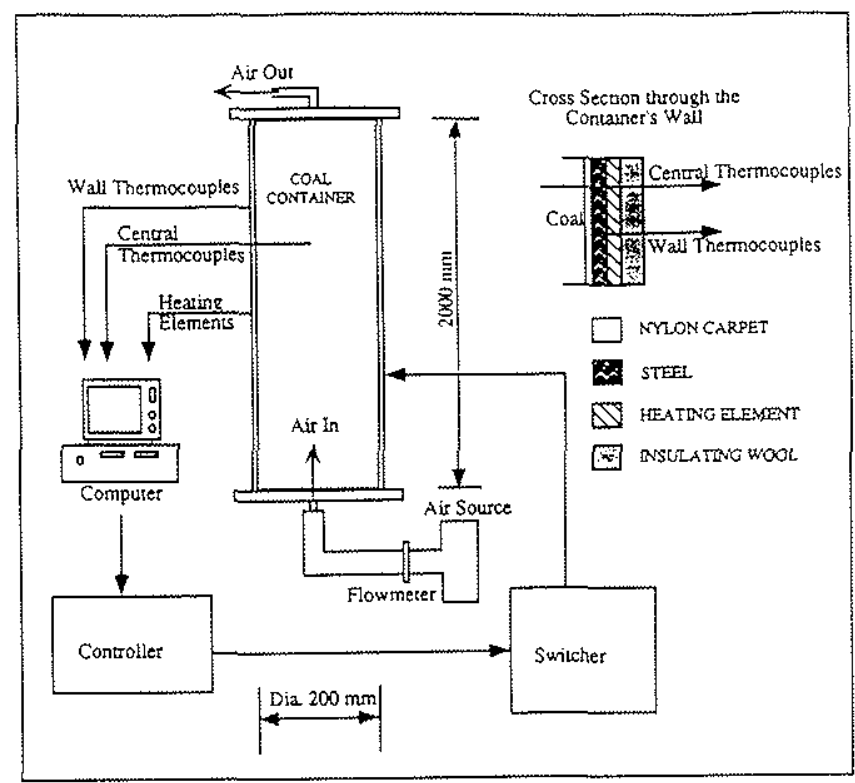

Fic 1 - Schematic diagram of stockpile model for spontancous combustion testing apparatus.

the temperature on the outside of the steel tube is lower than that at the column centre until temperatures are equal. The intention is to avoid loss of heat from the tube. Each heating element operates independently of the others. Airflow through the column is delivered from a compressed air line and is set for the duration of each experiment. At the first stage, $10 \mathrm{~mm} /$ minute velocity of air ( $314 \mathrm{ml} /$ minute) is used, based on the results of experiments undertaken by previous researchers (Stott and Chen, 1992). However, the next tests may choose different airflow rate. One aim of the study is to determine the airflow rate that maximises the propensity to coal spontaneous combustion with other conditions fixed.

\section{SOME EXPERIMENTAL RESULTS FROM USE OF THE MODEL}

Some results from use of the model are given to illustrate its usage. Test 1 results were undertaken on Mine A coal taken from the washery plant stockpile. Figure 2 shows the distribution of the temperature within the column at time intervals during the test and Figure 3 shows the temperature rise against time at the column point of maximum temperature occurrence. It can be seen from the results of this experiment that the highest temperature within the column occurred at the location $800 \mathrm{~mm}$ from air inlet. A temperature of about $100^{\circ} \mathrm{C}$ was reached 25 days into the test and soon after that the temperature rose dramatically, peaking at $153^{\circ} \mathrm{C}$.

Test 2 was undertaken on Mine A coal as delivered to a power station stockpile. The results of this experiment are shown in Figures 4 and 5 respectively. Because of the dramatic rise in Test 1 coal temperature, once $100^{\circ} \mathrm{C}$ maximum column temperature was reached, a cutout circuit was incorporated in the apparatus to stop the test at $100^{\circ} \mathrm{C}$ for safety reasons.

Figures 6 and 7 show the results of rest 3 which was undertaken on Mine B coal taken from the washing plant stockpile. Similarly, Figures 8 and 9 show the results of Test 4 which was undertaken on Mine B coal taken from the power station stockpile.

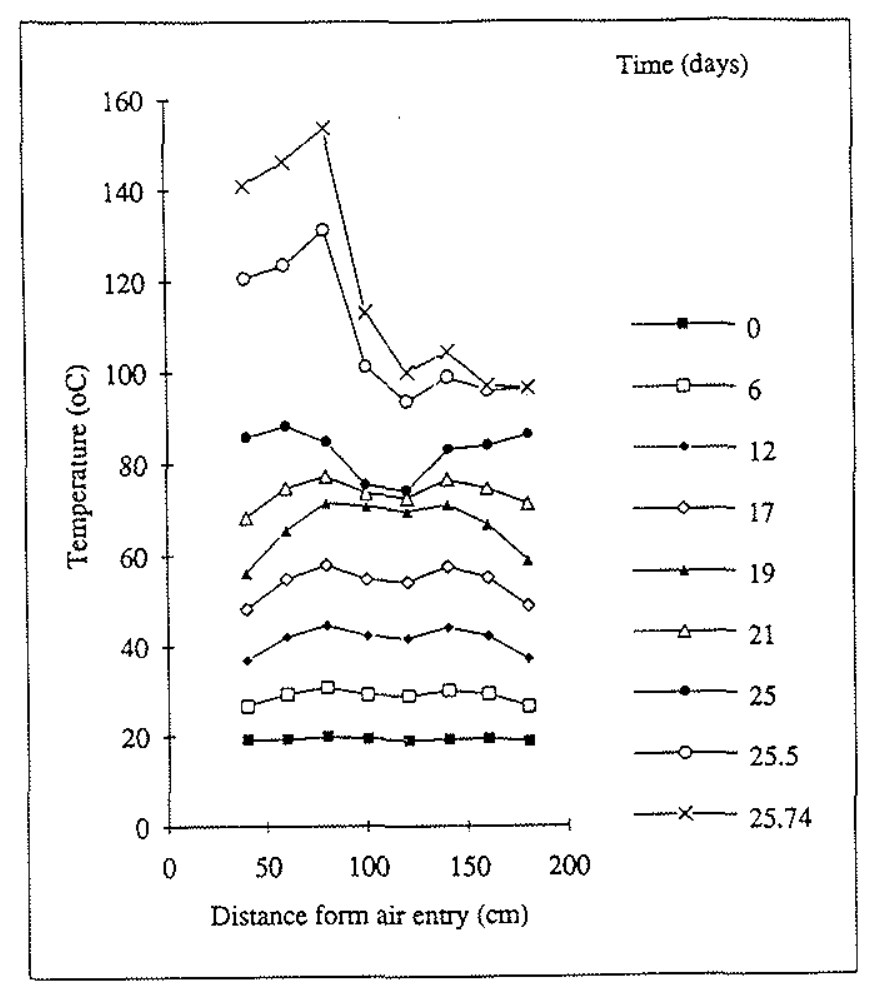

Fug 2 - Temperature distribution of Mine A washery product coal.

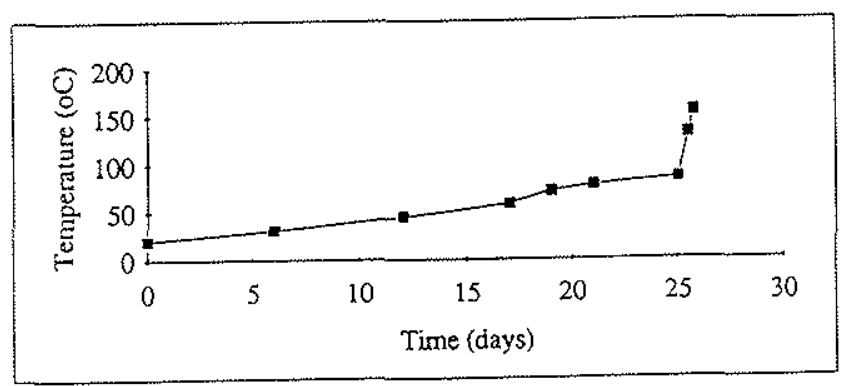

FIG 3 - Temperature rise of Mine A washery product coal.

From the results of the above tests, it can be seen that in general, the highest temperature was reached at about the same location, that is about $800 \mathrm{~mm}$ from air inlet, but the distribution of the temperature within the column for the last three tests was more even compared to the first test. If a comparison between Test 1 and Test 2 is made, as both are dealing with Mine A coal, the main difference was that it took about 25 days to reach $100^{\circ} \mathrm{C}$ for Test 1 , compared to about only 17 days for Test 2 . Similar results are also shown by Tests 3 and 4 . It took about 18 days to reach $100^{\circ} \mathrm{C}$ for Test 3 using Mine $B$ coal taken from washery plant stockpile and only about 12 days was needed to reach the same temperature for similar coal collected from the power station stockpile. A preliminary conclusion can be made that coal collected from the power station stockpile is more liable to spontaneous combustion than similar coal from the washing plant stockpile. It is suggested that changes in moisture level and degradation in coal particle size exposing more oxidation surfaces would contribute to explaining this change. 


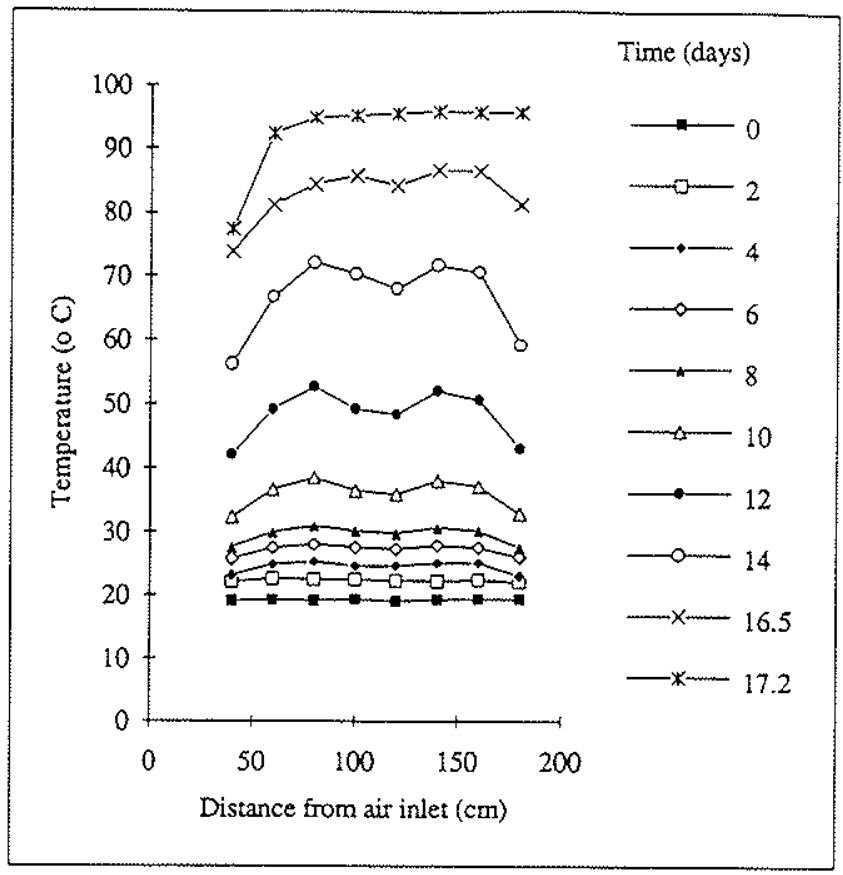

FIG 4 - Temperature distribution of Mine A coal received at power station.

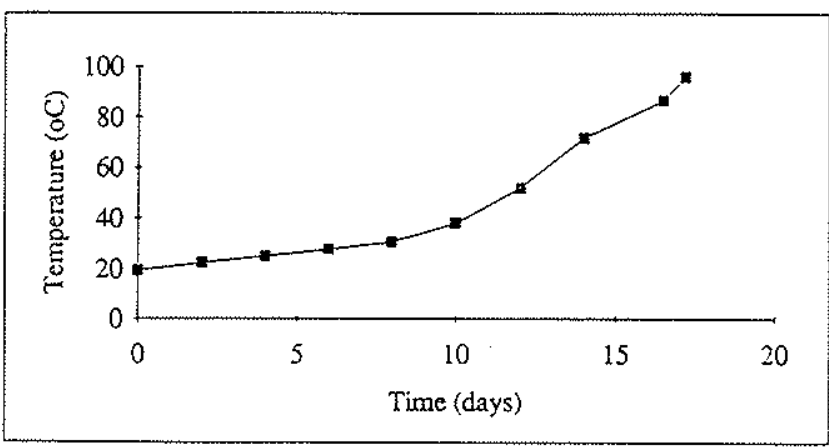

FIG 5 - Temperature rise of Mine A coal received at power station.

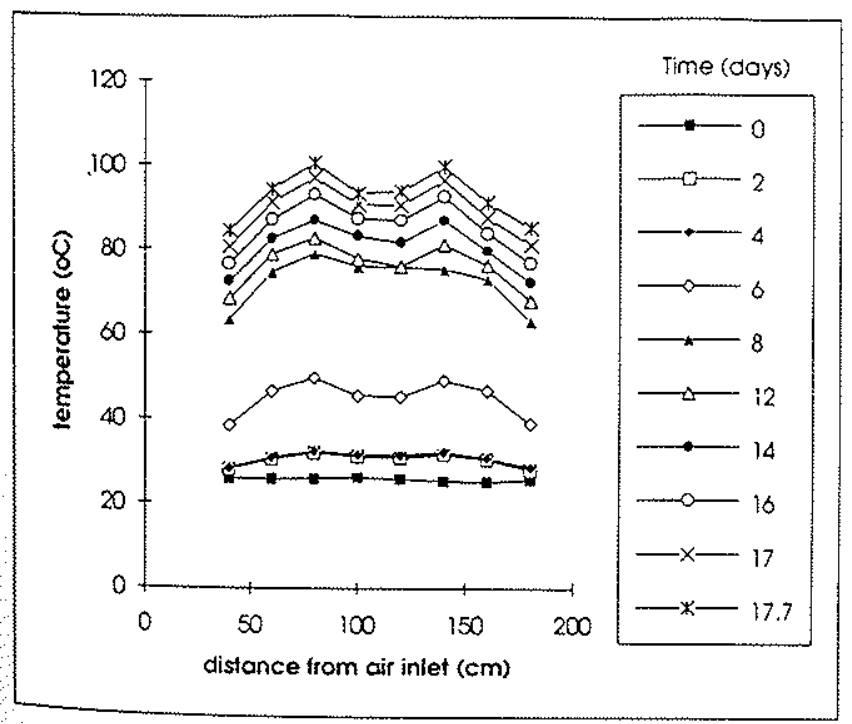

FIG 6 - Temperature distribution of Mine B washery product coal.

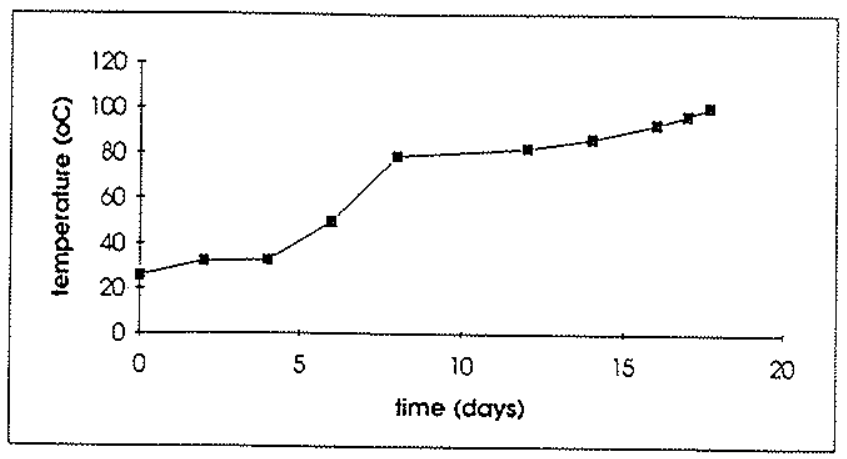

FIG 7 - Temperature rise of Mine B washery product.

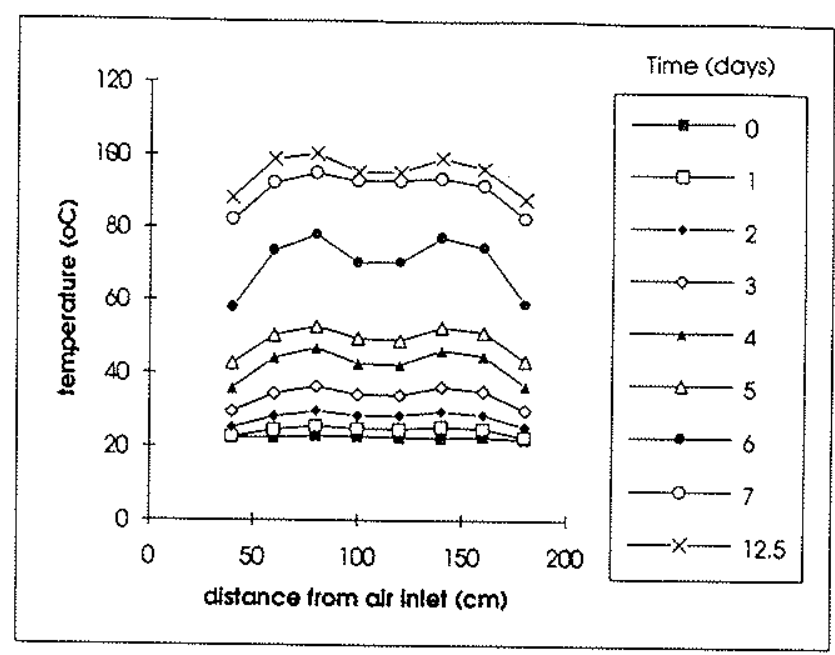

Fig 8 - Temperature distribution of Mine B coal received at power station.

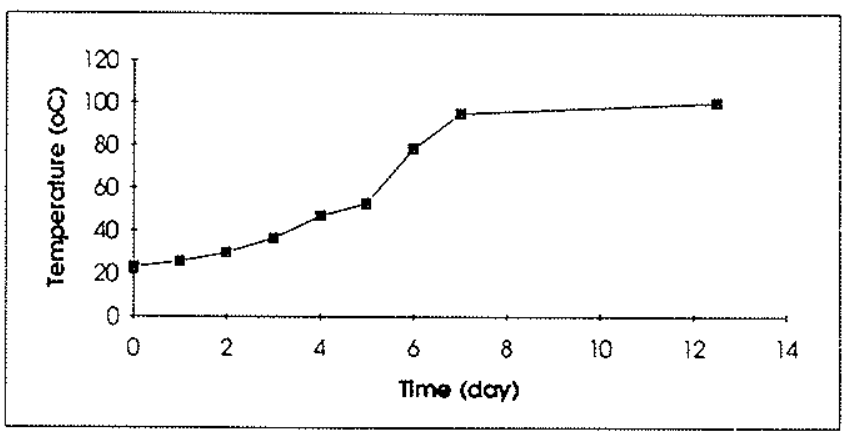

FlG 9 - Temperature rise of Mine B coal received at power station.

\section{DISCUSSION}

A device has been developed for modelling the behaviour of coal under conditions which may lead to spontaneous combustion. It is designed to simulate the behaviour of a stockpile due to use of an insulated wall heating system that effectively stops heat loss from the coal mass and so resembles a stockpile of large mass. The apparatus tests behaviour of coal which has been sampled from the mine, plant, stockpile or transport unit without intermediate preparation. For this reason, it has the potential to reflect field conditions with reasonable accuracy. 
Possible applications of the test apparatus can be categorised as follows.

1. Mining practice: Whenever broken coal or coal and surrounding strata accumulate over time, potential exists for spontaneous combustion. Examples include goaf material, material stored 'temporarily' underground, blasted surface coal which is delayed in removal and overburden dumps.

2. Stockpiles: Large stockpiles can occur before and after the washing plant, at intermediate shipping points and at the utilisation site. Residence times at the stockpile are important as are the compaction characteristics of the stockpile.

3. Transportation: Time involved in transportation, moisture content and particle size are important aspects.

\section{CONCLUSION}

The practical model for spontaneous combustion testing, at a preliminary stage, has shown a potential to test coal sampled in the natural state from various points in the coal flow path from mine to point of utilisation. By testing coal in an 'as sampled' condition it may be able to give reliable estimates of the effects of particle size and moisture content on propensity for spontaneous combustion to occur. Different degrees of compaction can be achieved and airflow rate varied to study the effects of varying rates of air permeation on the coal oxidation process. Future work will quantify these effects.

\section{REFERENCES}

Chen, X D, 1991. The Spontaneous Heating of Coal; Large Scale Laboratory Assessment and Supporting Theory. PhD Thesis, Chemical Engineering, University of Canterburry, New Zealand.

Humphreys, D and Hester, C, 1994. Spontancous Combustion and Fires and Mine Gases in Proceedings Mining Ventilation Short Course, (Ed: A D S Gillies), (Centre for Mining Technology and Equipment).

Isobe, $\mathrm{T}$ and Higuchi, $\mathrm{T}, 1981$. Theoritical and experimental research on occurrence of spontaneous combustion of coal scam, Proceedings Ignition, Explosions and Fires (Ed: A J Hargraves), p4/1-4/15 (The Australasian Institute of Mining and Metallurgy: Wollongong).

Stott, J B and Chen, X D, 1992. Measuring the tendency of coal to fire spontancously in Collieny Guardian 240(1): 9-16. 